\title{
Value Orientations of College Students with Different Status of Professional Identity
}

\author{
Yulia Popova $^{1},{ }^{*}$ Valery Petkov ${ }^{1}$, Veronika Grebennikova ${ }^{1}$, Konstantin Shkuropy $^{2}$ \\ ${ }^{1}$ Kuban State University, Russia \\ ${ }^{2}$ State Pedagogical University of Armavir, Russia \\ *Email: jeis@mail.ru
}

\begin{abstract}
This study aims to identify the meaningful relationship of personal value orientations depending on professional identity status. The article presents the results of a study of students' value orientations of a pedagogical college with different professional identity status. The data obtained based on the conducted correlation and frequency analysis allow concluding that there are substantial and structural differences in the value sphere of students of a pedagogical college due to professional identity development level. The study results indicate that the value sphere of students with achieved professional identity is characterized by an integral structure, where the leading values are associated with selfleadership, self-actualization, and self-development. Among students with a crisis of professional identity, the value sphere is characterized by partial instability and an active search position concerning resources, support and means of self-development. For students with an indefinite and imposed professional identity, the value sphere's state reflects an insufficient readiness for professional development. The factors of the system formation of value orientations are the conditions promoting professional self-determination, as indicated by the simplified structure of students' values with an immature and emerging professional identity.
\end{abstract}

Keywords: Identity, Professional identity, Professionalization, Career guidance, Identity status, Value orientation.

\section{INTRODUCTION}

The professionalization of a person during studying at the college is associated with the acquisition of such professional competencies, which correlate, on the one hand, with the essential characteristics of the individual and his basic abilities, which constitute the zone of growth and self-actualization, and, on the other, with the learning conditions that, to varying degrees, contribute to the formation of a professional important qualities. In his study, J. Ursin considers the conceptual foundations of pedagogical activity as one of the significant elements of forming the professional orientation of the teacher's personality. It is emphasized that "to understand and support the formation of the teacher's identity, special attention should be paid to the relationship between individual and collective needs" [1, p.233]. In S. Efu's work, an important condition for forming teachers' professional identity is the possibility of continuous professional development [2]. At the same time $\mathrm{S}$. Brownell and $\mathrm{K}$. Tanner draw attention to possible barriers in the formation of a professional-pedagogical identity caused by excessive polarization: "while forming a pedagogical identity, novice scientists potentially risk their status as researchers, and their professional identity, status and even membership in the scientific community" [3, p.342]. M. Clarke, A. Hyde and J. Drennan [4] studied the complicity and instability of professional identity and dependence on contextual factors. F. Castañeda, in his research, described the relationship of knowledge, beliefs and teaching practice with the construction of the professional identity of future teachers, emphasizing that "self-realization and professional development are likely to determine a more stable identity in the future" $[5$, p.62]. In study of T. Kintz, J. Lane et al is shown that the effectiveness of teaching future teachers is due to the possibility of applying the acquired knowledge in practice, while reflection, feedback and learning in 
cooperation are also important factors [6]. In study of K. Palermo and M. Thomson using multiple regression analysis, the systemic relationships of motivation, values, awareness of teachers' own abilities are considered as predictors of the implementation of teachers' professional activities [7]. Work of E. Boström and T. Palm shows the possibilities of applying the theory of expected value as an element of achievement motivation to explain changes in teachers' activities [8] and the study of C. Andersson and T. Palm, the importance of understanding the essential characteristics of teachers' teaching process and the possibilities of self-regulation for the subjectification of the teaching process is actualized [9]. The influence of the gender characteristics of the self-concept on the formation of identity is presented in the work of $\mathrm{Yu}$. Popova, V. Petkov et al. [10].

Consequently, the integrativeness of the valuesemantic sphere, its depth and fullness, correlate with mastering professional activity in the learning process, which is reflected in the qualitative relationship of the value attitude to various aspects of reality and the level of achieved professional identity. The validity of this statement is confirmed by the study of value orientations of students of a pedagogical college presented in the article with different professional identity levels.

\section{STUDY RESULTS}

To study value orientations, the methods of $\mathrm{M}$. Rokich and S. Bubnova were used; to diagnose the status of professional identity - the method of A. Azbel [11]. The research was carried out in Krasnodar's pedagogical college on a sample of 3-year students in the number of 50 people. Per the achieved status of professional identity, the respondents were divided into subgroups in each of which the hierarchies of value orientations were considered and their interrelationships. Four subgroups of respondents were identified. Subgroup 1 - respondents with an unformed professional identity; subgroup 2 respondents with an imposed professional identity; subgroup 3 - respondents experiencing a crisis, forming professional identity; subgroup 4 - respondents with a formed professional identity. Average group rank indicators of values are presented in the tables below.

Note: 1 - active life; 2 - life wisdom; 3 - health; 4 interesting work; 5 - the beauty of nature and art; 6 - love; 7 - materially secure life; 8 - having good and loyal friends; 9 - public recognition; 10 - cognition; 11 - a productive life; 12 - development; 13 - entertainment; 14 - freedom; 15 - happy family life; 16 - the happiness of others; 17 - creativity; 18 - self-confidence.

Table 1. Average group rank indicators of terminal values (according to the questionnaire of M. Rokich)

\begin{tabular}{|l|c|c|c|c|}
\hline \multirow{2}{*}{ Value } & \multicolumn{4}{|c|}{ Subgroup } \\
\cline { 2 - 5 } & 1 & 2 & 3 & 4 \\
\hline 1 & 11.900 & 9.000 & 9.600 & 10.958 \\
\hline 2 & 9.400 & 11.667 & 10.500 & 8.333 \\
\hline 3 & 2.700 & 4.333 & 6.600 & 4.417 \\
\hline 4 & 9.200 & 7.500 & 10.700 & 8.167 \\
\hline 5 & 13.700 & 16.500 & 12.600 & 14.417 \\
\hline 6 & 6.300 & 4.333 & 7.500 & 6.208 \\
\hline 7 & 7.200 & 7.667 & 7.200 & 7.667 \\
\hline 8 & 5.000 & 8.833 & 8.000 & 8.792 \\
\hline 9 & 14.000 & 12.167 & 12.000 & 12.792 \\
\hline 10 & 9.400 & 12.000 & 9.600 & 11.458 \\
\hline 11 & 10.000 & 11.167 & 9.200 & 9.083 \\
\hline 12 & 8.800 & 7.667 & 7.900 & 9.292 \\
\hline 13 & 11.900 & 13.833 & 11.300 & 12.375 \\
\hline 14 & 9.600 & 10.500 & 8.100 & 6.625 \\
\hline 15 & 4.600 & 2.667 & 9.800 & 6.208 \\
\hline 16 & 13.000 & 12.833 & 14.700 & 14.750 \\
\hline 17 & 14.200 & 10.833 & 11.500 & 12.667 \\
\hline 18 & 8.700 & 7.500 & 4.700 & 6.417 \\
\hline
\end{tabular}


Table 2. Average group rank indicators of the real value orientations of the individual (according to the questionnaire of S. Bubnova)

\begin{tabular}{|l|c|c|c|c|}
\hline \multirow{2}{*}{ Value } & \multicolumn{4}{|c|}{ Subgroup } \\
\cline { 2 - 5 } & 1 & 2 & 3 & 4 \\
\hline 1 & 4.400 & 4.833 & 4.700 & 4.833 \\
\hline 2 & 3.300 & 3.167 & 3.400 & 3.083 \\
\hline 3 & 2.500 & 3.833 & 3.100 & 2.792 \\
\hline 4 & 5.000 & 5.833 & 4.600 & 4.375 \\
\hline 5 & 3.200 & 4.000 & 4.000 & 3.833 \\
\hline 6 & 2.400 & 3.167 & 3.400 & 2.708 \\
\hline 7 & 3.300 & 3.667 & 3.400 & 2.875 \\
\hline 8 & 4.200 & 5.000 & 4.400 & 4.417 \\
\hline 9 & 2.600 & 3.000 & 3.300 & 3.042 \\
\hline 10 & 3.000 & 2.833 & 2.700 & 2.833 \\
\hline 11 & 3.200 & 3.000 & 2.200 & 2.958 \\
\hline
\end{tabular}

Note: 1 - a pleasant pastime; 2 - material well-being; 3 - enjoyment of the beautiful; 4 - mercy; 5 - love; 6 learning new things; 7 - social status; 8 - recognition; 9 social activity; 10 - communication; 11 - health.

The results of frequency and statistical analysis indicate that the identity statuses in the sample were distributed as follows:

- subgroup 1: vague, diffuse professional identity (lack of professional goals and plans for their formation, lack of ideas about their own professional development, insufficient awareness of the importance of professional self-determination) was noted in $20 \%$ of the sample (10 people). The most significant values for respondents with an indefinite professional identity: health (physical and mental), a happy family life, the presence of good and faithful friends, help and mercy to other people. The least significant values for respondents with an indefinite professional identity: the opportunity to engage in creativity, public recognition, the happiness of others, the experience of beauty in nature and art.

As shown by the correlation analysis (at $\mathrm{p} \leq 0.05$ ), among respondents with an indefinite professional identity, the aesthetic value of enjoying the beautiful decreases with an increase in the value of life wisdom and the possibility of engaging in creativity. Having good and loyal friends reduces the value of gaining recognition from others and influencing others. Good and faithful friends' presence increases the value of material wellbeing and knowledge of new things in the world, nature, and man. Recognition and respect of people, influence on others is accompanied by an increase in the value of expanding one's education, horizons, general culture, and intellectual development. The values of love, learning new things, and social activity to achieve positive changes in society are accompanied by increased awareness of the socially oriented value of other people's development and improvement.

- subgroup 2: imposed professional identity (the choice of a profession is due to external pressure from the reference circle of persons, superficial professional identification as a way of avoiding professional choice and self-determination) was noted in $12 \%$ of the sample (6 people). The most significant values of respondents with an imposed professional identity: a happy family life, spiritual and physical closeness with a loved one, physical and mental health, recognition and respect of people and influence on others, help and mercy to other people, a pleasant pastime, rest. The least significant values of respondents with an imposed professional identity: pleasant, unobtrusive pastime, the experience of beauty in nature and art.

The correlation analysis data carried out using Spearman's rank correlation criterion (at $\mathrm{p} \leq 0.05$ ) allows concluding that among respondents with an imposed professional identity, the value attitude to learning new things reduces the activity's value. The presence of good and loyal friends reduces the manifestation of the aesthetic value of delight in beauty. Recognizing and respecting people and influencing others reduces the hedonistic desire for a pleasant, easy time, lack of responsibilities. High material well-being and well-being in love reduce the value of happy family life. The opportunity to engage in creativity is accompanied by a decrease in social activity's value to achieve positive changes in society. Spiritual and physical closeness with a loved one reduces the value of the aesthetic pleasure of beauty. The value of material security is accompanied by a decrease in the desire for recognition and respect. Simultaneously, the wisdom of life and the value attitude to health increase the value of such socially oriented 
activity. The experience of beauty in nature and art is accompanied by the actualization of the orientation toward a pleasant pastime and rest. The value of a materially secured life, the possibility of an easy pastime, the absence of responsibilities, the ability to engage in creativity correlate with the high value of health. High social status and management of people correlate with the fullest use of one's capabilities, strengths and abilities. While work on oneself, constant physical and spiritual improvement is accompanied by an awareness of the value of a pleasant pastime, relaxation and love;

- subgroup 3: the status of a crisis choice of identity, or emerging identity (reflections on possible ways of professional development, an active research position concerning professional roles, attempts to try on various professional roles, an unstable position) was noted in $20 \%$ of the sample (10 people). The most significant values of respondents with a crisis of professional identity: inner harmony, freedom from internal contradictions, help and mercy to other people, a pleasant pastime, rest. The least significant values of respondents with a crisis of professional identity: the happiness of others, the beauty of nature and art, health.

The correlation analysis (at $\mathrm{p} \leq 0.05$ ) among respondents with a crisis of professional identity allowed us to conclude that with an increase in the value attitude to wisdom in life, there is a decrease in the desire to seek and enjoy the beauty. The actualization of spiritual and physical closeness with a loved one, a happy family life leads to a decrease in the value attitude towards others' recognition and the ability to influence them. High social status and the ability to manage people are accompanied by a decrease in public recognition's relevance. The possibility of expanding one's education, outlook, general culture, the possibility of learning new things in the world and nature, self-confidence, inner harmony, freedom from internal contradictions, doubts, accompanied by leads to a decrease in the hedonistic value of rest and pleasant pastime. With the increase in the value of love and health, the value of a materially secured life is also actualized. Having good and loyal friends, developing possibility and improving other people correlate with a pleasant pastime value. The possibility of expanding one's education, horizons, general culture, intellectual development, self-confidence, inner harmony, as well as a pleasant, easy-going pastime correlate with the value of helping other people, with gaining recognition and respect from others and the ability to influence others. The ability to engage in creativity correlates with the importance of social activity for achieving positive changes in society;

- subgroup 4: achieved professional identity (readiness to make a professional choice, readiness for professional self-determination, confidence in the correctness of the decision made, the presence of independently formed beliefs about their own professional choice) was noted in $48 \%$ of the sample (24 people). The most significant values of respondents with achieved professional identity: self-confidence, inner harmony, happy family life, independence, independence in judgments and actions, spiritual and physical closeness with a loved one, physical and mental health, recognition and respect of people and influence on others, a pleasant pastime, rest. The least significant values of respondents with achieved professional identity: the ability to engage in creativity, the happiness of others, a pleasant, unobtrusive pastime, the absence of responsibilities, public recognition, the experience of beauty in nature and art, knowledge of new things in the world, nature, and man.

As shown by the correlation analysis (at $\mathrm{p} \leq 0.05$ ), having an interesting job reduces the focus on seeking and enjoying beauty among respondents with achieved professional identity. High social status and people's management leads to a decrease in the aesthetic value of the perception of beauty in nature and art, reducing the focus on enjoying the beauty. The value of spiritual and physical intimacy with a loved one, the presence of good and faithful friends, reduces the value of abstract love. A decrease in communication accompanies the value of social recognition and the value of a happy family life. The value of the possibility to help other people leads to a decrease in the value of a pleasant, easy-going pastime, lack of responsibilities. An increased focus on enjoying the beautiful, learning new things in the world, nature, and man is accompanied by a decrease in the desire to engage in creativity. An active life, the acquired wisdom of life, is accompanied by the actualization of the desire to help others. Realization of the value of physical and mental health is accompanied by the desire to learn new things. A financially secure life, self-confidence, and inner harmony are accompanied by recognizing the value of love. The possibility of the fullest possible selfrealization correlates with the recognition of the value of communication. High material well-being determines the ability to engage in creativity.

Statistical analysis using the Kruskell - Wallace H test made it possible to establish significant differences between respondents with different identity status - the value of helping other people is significantly higher for respondents with a higher identity status $\left(\chi^{2}=15.581\right.$ at $\mathrm{p}$ $=0.008)$. This is also confirmed by analysis using the Mann-Whitney $U$ test in a pairwise comparison of subgroups.

The value of delight in the beautiful is higher for respondents with an unformed identity than respondents with an imposed identity $\left(\mathrm{U}_{\mathrm{emp}}=7.500\right.$ at $\left.\mathrm{p}=0.005\right)$.

The value of health $\left(\mathrm{U}_{\mathrm{emp}}=22.000\right.$ at $\left.\mathrm{p}=0.030\right)$, the value of learning new things in the world and nature $\left(\mathrm{U}_{\mathrm{emp}}=24.000\right.$ at $\left.\mathrm{p}=0.040\right)$ is higher among respondents with an unformed identity compared to respondents with an identity crisis, and the value of inner harmony, 
freedom from internal contradictions, doubts - lower $\left(\mathrm{U}_{\mathrm{emp}}=7.500\right.$ at $\left.\mathrm{p}=0.001\right)$.

The value of having loyal friends is higher $\left(\mathrm{U}_{\mathrm{emp}}=121.000\right.$ at $\left.\mathrm{p}=0.041\right)$, and the value of helping other people is lower $\left(U_{e m p}=373.500\right.$ at $\left.p=0.046\right)$ for respondents with an unformed identity compared to respondents with a formed identity.

The value of helping other people is also higher for respondents with an identity crisis $\left(\mathrm{U}_{\mathrm{emp}}=9.000\right.$ at $\mathrm{p}=0.015)$ and with a formed identity $\left(\mathrm{U}_{\mathrm{emp}}=9.500\right.$ at $\mathrm{p}=0.001$ ) compared to respondents with an imposed identity.

\section{RESULTS DISCUSSION}

Thus, for the effective formation of professional identity in the process of studying in college, it is necessary to create conditions that orient students to actualizing the abilities to construct their own activity in the direction of self-development, assistance in the selforganization of activities, as well as the orientation of students to professionally important goals and meanings. At the same time, special attention should be paid to students with an identity crisis, since if they focus on professional development and awareness of their value, they do not have self-leadership skills, which is typical for this sensitive stage of identity formation. Consequently, special attention in the pedagogical process should be paid to those types of activity that correlate with the acquisition and development in the proposed conditions of personality-oriented selfdevelopment tools, taking into account the expressed values and meanings.

\section{CONCLUSION}

The carried out a meaningful analysis of the value orientations of pedagogical college students with different status of professional identity shows that the achieved professional identity correlates with a more integral structure of values, among which the values of self-actualization, self-leadership, focus on selfdevelopment take a significant place. The status of the emerging identity (or identity crisis) is more correlated with the values of the social order and the focus on selfdevelopment, which indicates the resource nature of these areas of life for the emerging personality. The content of students' value with the status of imposed identity reflects their dependence on society, insufficient maturity and competence, the predominantly hedonistic orientation of activity. The value orientation of students' personality with an unformed professional identity indicates the insufficient stability of the value-semantic sphere, in which the values of social, aesthetic and hedonistic orientation are distinguished, but without a pronounced focus on self-management and selforganization.

\section{REFERENCES}

[1] J. Ursin, S. Paloniemi, "Conceptions of teachership in the professional identity construction of adult educator graduates", Teacher Development 23:2 (2019) 233-248. DOI: https://doi.org/10.1080/13664530.2019.1575274

[2] S.I. Efu, "An evaluative inquiry into continuing professional development: understanding faculty perceptions", Teacher Development 24:5 (2020) 688-708.

DOI: https://doi.org/10.1080/13664530.2020.1823463

[3] S.E. Brownell, K.D. Tanner. "Barriers to Faculty Pedagogical Change: Lack of Training, Time, Incentives, and ... Tensions with Professional Identity?" CBE - Life Sciences Education 11(4) (2012) 339-346. DOI: https://doi.org/10.1187/cbe.12-09-0163

[4] M. Clarke, A. Hyde, J. Drennan, "Professional Identity in Higher Education." In The Academic Profession in Europe: New Tasks and New Challenges, edited by B. M. Kehm and U. Teichler, 2013, 7-21. Dordrecht: Springer Netherlands. DOI: https://doi.org/10.1007/978-94-007-4614-5_2

[5] J.A.F. Castañeda, "Learning to Teach and Professional Identity: Images of Personal and Professional Recognition", PROFILE Issues in Teachers' Professional Development 16(2) (2014) 49-65.

DOI:

https://doi.org/10.15446/profile.v16n2.38075

[6] T. Kintz, J. Lane, A. Gotwals, D. Cisterna. "Professional Development at the Local Level: Necessary and Sufficient Conditions for Critical Colleagueship." Teaching and Teacher Education 51 (October) 2015, pp. 121-136. DOI: https://doi.org/10.1016/j.tate.2015.06.004

[7] C. Palermo, M.M. Thomson Large-scale assessment as professional development: teachers' motivations, ability beliefs, and values, Teacher Development 23:2 (2019) 192-212. DOI: https://doi.org/10.1080/13664530.2018.1536612

[8] E. Boström, T. Palm, Expectancy-value theory as an explanatory theory for the effect of professional development programmes in formative assessment on teacher practice, Teacher Development 24:4 (2020) 539-558. DOI: https://doi.org/10.1080/13664530.2020.1782975

[9] C. Andersson, T. Palm, "Reasons for Teachers' Successful Development of A Formative Assessment Practice through Professional Development: A Motivation Perspective." Assessment in Education: Principles, Policy \& 
Practice 25(6) (2018) 576-597. DOI: https://doi.org/10.1080/0969594X.2018.1430685

[10] Y. Popova, V. Petkov, A. Balyk, K. Bulakh, I. Glushchenko "Gender characteristics of selfconcept among students-athletes" BIO Web Conf., $26 \quad$ (2020) $00052 . \quad$ DOI: https://doi.org/10.1051/bioconf/20202600052

[11] Diagnostics of professional self-determination / ed. Suntsova Ya.S. Izhevsk: Udmurt University Press, 2009, $112 \mathrm{p}$. 